\title{
Does Talking about Emotion Help Eyewitness Memory? The Role of Emotional and Factual Retelling in Memory Accuracy
}

\author{
Kartini Abdul Ghani ${ }^{1^{*}}$ \\ Lau Choon Ning ${ }^{2}$
}

${ }_{1,2}$ Universiti Malaysia Sarawak, 94300 Kota Samarahan, Sarawak, Malaysia

\begin{abstract}
Eyewitnesses typically talk about the traumatic events that they have experienced based on their memory. This research aimed to investigate differences between emotional and factual retelling of eyewitness in terms of memory accuracy and error. Participants watched a traumatic robbery video and were instructed to recall the events in detail. Participants were divided into three retelling conditions where they: a) discussed the robbery in a factual way, b) focused on discussing their emotional response, and c) performed unrelated tasks. Results showed that eyewitnesses who talked about their emotion recalled less detailed memories and made more errors in free recall while eyewitnesses who focused on factual detail seem to be able to maintain their memory accuracy of the event.
\end{abstract}

Keywords: eyewitness memory; emotional retelling; factual retelling; memory accuracy; memory error

\section{INTRODUCTION}

Recently, there is an alarming rise of criminal acts in our society. Armed robbery, murder case and rape case are just a few examples which can happen to anyone anywhere. When a crime happens, an eyewitness testimony

\section{ARTICLE INFO}

E-mail address:

gkartini@unimas.my (Kartini Abdul Ghani)

*Corresponding author

ISSN: 2462-1153

(C) Faculty of Cognitive Sciences and Human Development, Universiti Malaysia Sarawak (UNIMAS) plays an important role to provide information about the crime. It is common when someone witnessed a crime, he or she will be interviewed especially by law enforcers to gather detailed information about the traumatic event. Eyewitness memory is an example of the memory recall that enables eyewitness to think back to the event that had happened in the past. There were numerous studies with regards to eyewitness memory conducted in western countries, 
placing great importance on the accuracy in their stories (Loftus et al., 1987, 1991; Marsh, Tversky \& Hutson, 2005; Soleti et al., 2012). However, there is scarce eyewitness memory research conducted in Malaysia and with the high crime rates indicated by The Malaysia 2015 Crime and Safety Report, there should be a platform where this topic is investigated.

The accuracy and reliability of eyewitness testimony has often been of concern especially to those who were falsely convicted of the crime. It is important to decide how much to believe the eyewitness because there were many real-life cases that have been seen in which eyewitness testimony is inaccurate (Eysenck, 2006). Many people who had been convicted because of eyewitness testimony were cleared of the crime by DNA evidence, subsequently (Bohannon, 2014). This shows that eyewitness testimony is not entirely accurate. In addition, Bohannon (2014) also shows that $75 \%$ of convictions that is based on eyewitness testimony for rape and murder, including those scheduled for execution were actually wrong. Thus, eyewitnesses' testimony can differ from what had actually happened, even though they believed what they are describing was really happened.

A few studies have shown that witnesses often fail to recall back the event or even reported inaccurate information (Davies \& Logie, 1993). Experimental researchers explored different conditions that might improve or impair memory accuracy of eyewitness. When people witness an unexpected event, they may feel threatened and distracted. People may not notice the visual differences in the details of a scene. Hence, what they actually get to store in their memory is full of gaps. Our brain will fill in the gaps unconsciously with inferences and deductions that are not very reliable. This phenomenon is known as change blindness. As we are not aware of this processes, we concluded and believed that the reconstructed memory is what we actually witness (Wells, 2014). As a result, every time a person retrieves a false memory, it actually strengthens the false memory. In the end, people may confidently believe what they saw, even though it may differ from what had actually happened (Wells, 2014).

\section{Eyewitness Memory and Emotion}

There are different factors that can influence human's memory. Many researchers believe that emotions play an important role in what we remember (Zimmermann, 2014). Negative emotions may enhance or impair memory recalled. The theory of flashbulb memory by Brown and Kulik (1977) stated that people have clear memory of what had happened in events when they were emotionally involved. Flashbulb memory is focusing on memory for one's own personal situations, such as, where he/she was when the event is developing, what he/she was doing, and how he/she felt when he/she heard or experienced the news. Brown and Kulik (1977) state that people stored the memory automatically if that was a surprising and out of ordinary event, such as, witnessing a crime. Whitaker (2013) proved that people remember information easier if it is accompanied by emotional event. Emotionally charged incidents are remembered better. Besides, the stronger the emotions aroused, the larger the effect on memory.

Edelstein, Alexander, Goodman and Newton (2004) suggested that an individual who witnesses or experiences a negative event (who has negative emotional valence) may be particularly accurate when recalling the events. Ochsner (2000) stated that someone who experiences negative event, such as, assault has negative emotion and this negative emotion enhances the memory performance. Heuer and Reisberg (as cited in Ellis \& Hunt, 1993, p.355) stressed that negative or unpleasant events can be remembered well. All of them believed that an eyewit- 
ness who endures some level of emotional arousal is more attentive to relevant important cues and unimportant cues will receive less attention. This situation can benefit the performance of memory recall. While emotions can motivate memory, findings from a few studies cited some drawbacks - emotion also has a role in reducing memory accuracy. Kassin, Ellsworth and Smith (as cited in Ellis \& Hunt, 1993, p.355) strongly believed that emotional stress impairs the accuracy of eyewitness testimony. Anderson and Shimamura (2005) found that negatively emotional valence reduced the memory performance. Neissier and Harsch (as cited in Ellis \& Hunt, 1993, p.356) also proved that poorer recall was the result of stronger negative emotions.

Soleti, Curci, Bianco and Lanciano (2012) argued that the techniques of interviewing and ways to ask questions to those who were present during the event can influence the report of eyewitness testimony. They carried out a research about the role of emotional retelling and factual retelling on memory accuracy in eyewitness. In their research, participants were shown a video involving heated arguments between strangers and then the participants who are now witnesses were assigned to three different retelling conditions: emotional retelling (focus on emotion of witness), factual retelling (focus on facts of event) and control condition. Their results showed that in the emotional retelling condition, participants recall less detailed information about the event, while those in the factual retelling condition were prevented from deteriorating impairment of memory overtime. All the above findings indicated that emotion can influence the memory accuracy of eyewitness - eyewitness who focused on emotion and feeling has poor memory performance. According to studies investigating errors in eyewitness identification, someone who witnesses a traumatic emotional event will receive emotional stress and then causes less accurate in recall process (Brown \& Kulik, 1977; Dudukovic Dubrow \& Wagnerl, 2009; Wells, 2014). High stress or anxiety when witnessing an unusual case, could also implicate reduced attention and neglecting of the important cues (Loftus, Loftus, \& Messo, 1987; Marsh, Tversky \& Hutson, 2005; Anderson \& Shimamura, 2005).

The above literature suggested two opposite trends in findings - emotion can enhance memory, and emotions too can impair eyewitness memory. This inconsistency, however, shows how crucial the role of emotion is on memory retrieval of eyewitness. This research investigated further the role of emotional retelling and factual retelling on memory accuracy as well as measuring memory errors (additional measurement) in testimonies of eyewitness in Malaysian context.

\section{OBJECTIVE OF THE STUDY}

The main objective of this research is to examine the differences between testing stage on memory accuracy and memory error in different retelling conditions (Factual, Emotional and Control).

\section{Specific Objectives}

Specifically, the objectives of this study are:

i. To investigate whether there is a significant difference between pre and post-retesting memory accuracy scores based on the factual, emotional and control condition.

ii. To investigate whether there is a significant difference between pre and post-retesting memory error scores based on the factual, emotional and control condition.

\section{METHODOLOGY}

A 3 × 2 mixed design experiment was uti- 
lized, with Retelling (factual vs emotional vs control) being the between-participants factor and Test-retest (pre-retelling vs postretelling) being the within-participants factor. The dependent measures were memory accuracy and memory errors of the detail recall of events witnessed.

\section{Participants}

Thirty undergraduate students from Universiti Malaysia Sarawak (UNIMAS) participated in this study. The sample size of 30 participants was estimated using G-power analysis, which is adequate to conduct repeated measure of ANOVA with effects of moderate size. During the retelling phase, participants were assigned to one of the three retelling groups (factual, emotional or control) in a group of ten individuals.

\section{Materials and Procedure}

Informed consent was obtained before the experiment was carried out.

\section{Initial Phase}

Participants were informed that they are taking part in a memory performance testing. Once they have signed the informed consent, they were shown a short video. The instrument used in this research was a short video with duration of three min- utes. The short video was a story about a robbery case that had happened in a liquor store. The video was recorded by a 24 -hour security camera on 21 May 2014 around 4 p.m. The video was downloaded from YouTube with the title of Rompakan Bersenjata Di Kedai Arak Pada Siang HariArmed Robbery in a Liquor Store in Broad Day Light (Core, 2013). Before the incident happened, there were three women in the shop with a small child. Next, three Indian men (criminal) walked into the shop and pretended as customers. One of the criminals was tall and wore red-black stripe shirt. The other two were medium size men wearing a white-purple stripe shirt and a dark blue shirt. They asked the storekeeper to show the chosen liquor to them and they started to talk with each other in Tamil. They pretended to discuss on whether they wanted to purchase the bottle or not. They took out their wallet which indicated they wanted to pay but found that the money was not enough. Next, the man in the white-purple shirt pretended to go out to get some money from the automatic teller machine, whereas the others stayed in the shop. The man in the dark blue shirt kept talking through his mobile phone. The men waited until their friend came back from getting extra cash. Then, the man with the dark blue shirt cued the others and took out the parang. They used the weapon to threaten the storekeeper. They asked the shopkeeper to keep quiet and grabbed the

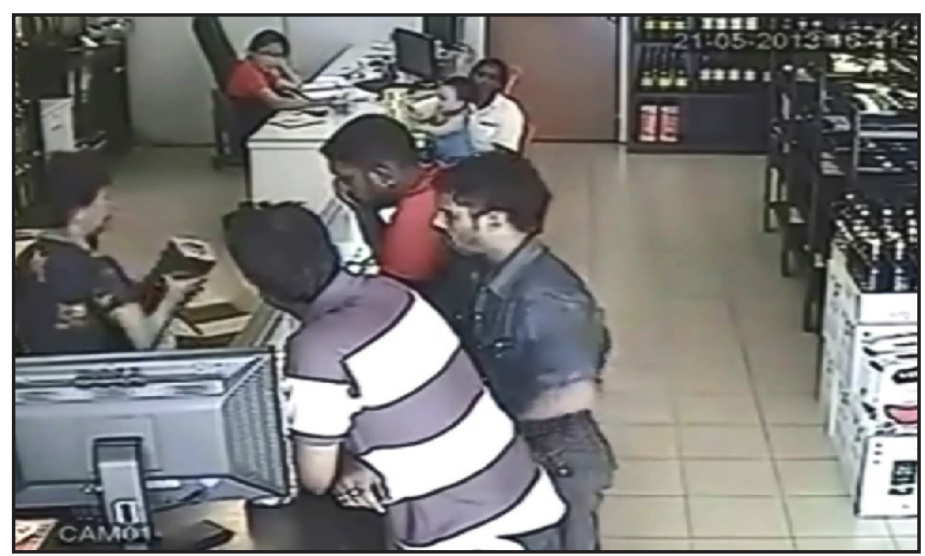

Figure 1: The criminal pretended as customer and storekeeper showed the liquor for them 


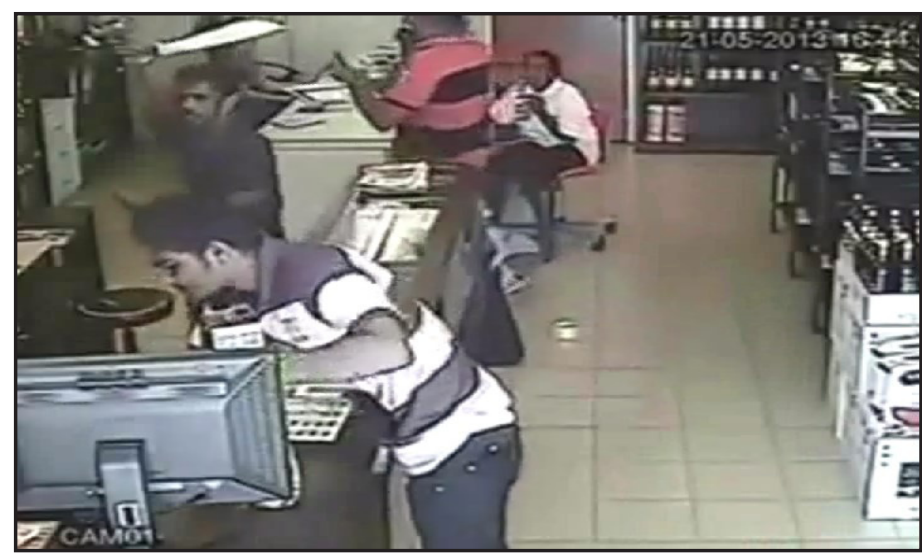

Figure 2: The criminal used parang to threaten victim

money-locker. They managed to rob the liquor store and ran away.

\section{Pre-retelling Free Recall Phase}

As soon as the participants completed the video session, they were given 10 minutes to write down as much details as they can of what they have witnessed in the video and reported the sequences of the event in the correct order as accurately as they can. At this stage, the task was performed individually.

\section{Retelling Phase}

In the retelling phase, all the 30 participants were instructed to form a group with ten individuals. The three groups were randomly assigned to one of the retelling conditions. Participants in the control condition group did not talk or discuss anything about the video they have seen but were instructed to perform an unrelated task, such as, Sudoku, a number game for five minutes. Participants in the emotional condition and factual condition groups were informed to discuss about the event of video within the group for five minutes. Participants in the emotional retelling condition talked about their emotional reactions while watching the video. They were asked to describe their thoughts and feelings about the event so that someone who has not seen the video can exactly imagine how they feel. While, participants in the factual retelling group discussed the event of video extensively. They talked about the detail fact and the sequence in which the event has occurred so that someone who has not seen the video can exactly imagine what had happened.

\section{Post-retelling Free Recall Phase}

After the retelling session within groups, participants were once again given ten minutes to write down a free narrative of the event in the video. This task was also performed individually. Instructions given were the same as the ones given in preretelling recall phase.

\section{Final Phase}

Lastly, the data (pre and post retelling information) were collected from all participants for analysis. The before and after response from the participants were analysed for accuracy by comparing their answers with the pre compile facts and information from the video and group scores were determined.

\section{RESULTS}

The data was analyzed using a $3 \times 2$ repeated measure ANOVA to investigate memory accuracy and memory error performance in between subjects Retelling 
Kartini Abdul Ghani and Lau Choon Ning

Table 1: Table of descriptive statistics for memory accuracy

\begin{tabular}{llll}
\hline Retelling & & & \\
\hline & $\begin{array}{l}\text { Factual } \\
(M, S D)\end{array}$ & $\begin{array}{l}\text { Emotional } \\
(M, S D)\end{array}$ & $\begin{array}{l}\text { Control } \\
(M, S D)\end{array}$ \\
\hline Pre-retelling & $9.40(0.52)$ & $9.30(0.48)$ & $9.9(0.57)$ \\
\hline Post-retelling & $10.50(0.53)$ & $8.30(0.48)$ & $9.20(0.78)$ \\
\hline \multicolumn{2}{l}{ Note: For all conditions, higher means indicate higher memory accuracy. }
\end{tabular}

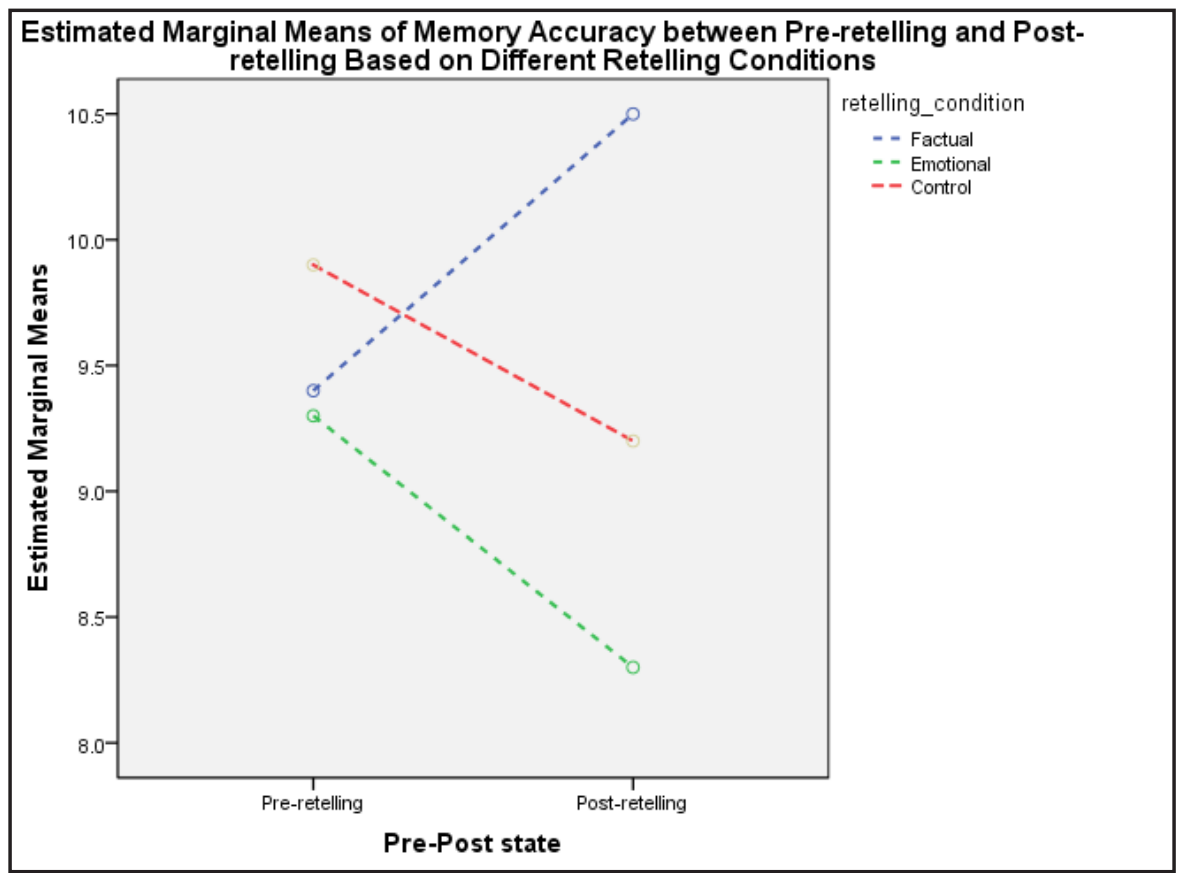

Figure 3: Interaction effect of retelling by test-retest on memory accuracy

conditions (factual vs emotional vs control) and within subjects Test-retesting conditions (pre and post memory recall).

\section{Memory Accuracy Performance}

Table 1 shows the mean and standard deviation for every $3 \times 2$ conditions for memory accuracy performance. The main effects of Retelling was found to be significant $(F=30.42, p<0.01)$, a significant increase in memory accuracy scores was reported between pre and post retelling state in the factual retelling group compared to emotional and control retelling groups. No significant difference was found between the Test-retest stage $(F=5.06)$. However, there was a significant interaction effect of retelling by test-retest at $F=33.82, p<0.01$ (see Figure 3).

Note: For all conditions, higher means indicate higher memory accuracy.

Figure 3 shows the interaction between retelling conditions and pre-post retelling state. the average mean of memory accuracy in factual retelling increases between the pre-retelling and post-retelling state. Instead, in the emotional and control condition a poor memory recall was shown between pre and post retelling.

\section{Memory Error Performance}

Table 2 shows the mean and standard deviation for every $3 \times 2$ conditions for memory 
Kartini Abdul Ghani and Lau Choon Ning

Table 2: Table of descriptive statistics for memory errors

\begin{tabular}{llll}
\hline Retelling & & & \\
\hline & $\begin{array}{l}\text { Factual } \\
(M, S D)\end{array}$ & $\begin{array}{l}\text { Emotional } \\
(M, S D)\end{array}$ & $\begin{array}{l}\text { Control } \\
(M, S D)\end{array}$ \\
\hline Pre-retelling & $9.40(0.52)$ & $1.80(0.63)$ & $2.90(0.57)$ \\
\hline Post-retelling & $1.70(0.48)$ & $2.70(0.68)$ & $3.40(0.52)$ \\
\hline
\end{tabular}

Note: For all conditions, higher means indicate higher memory accuracy.

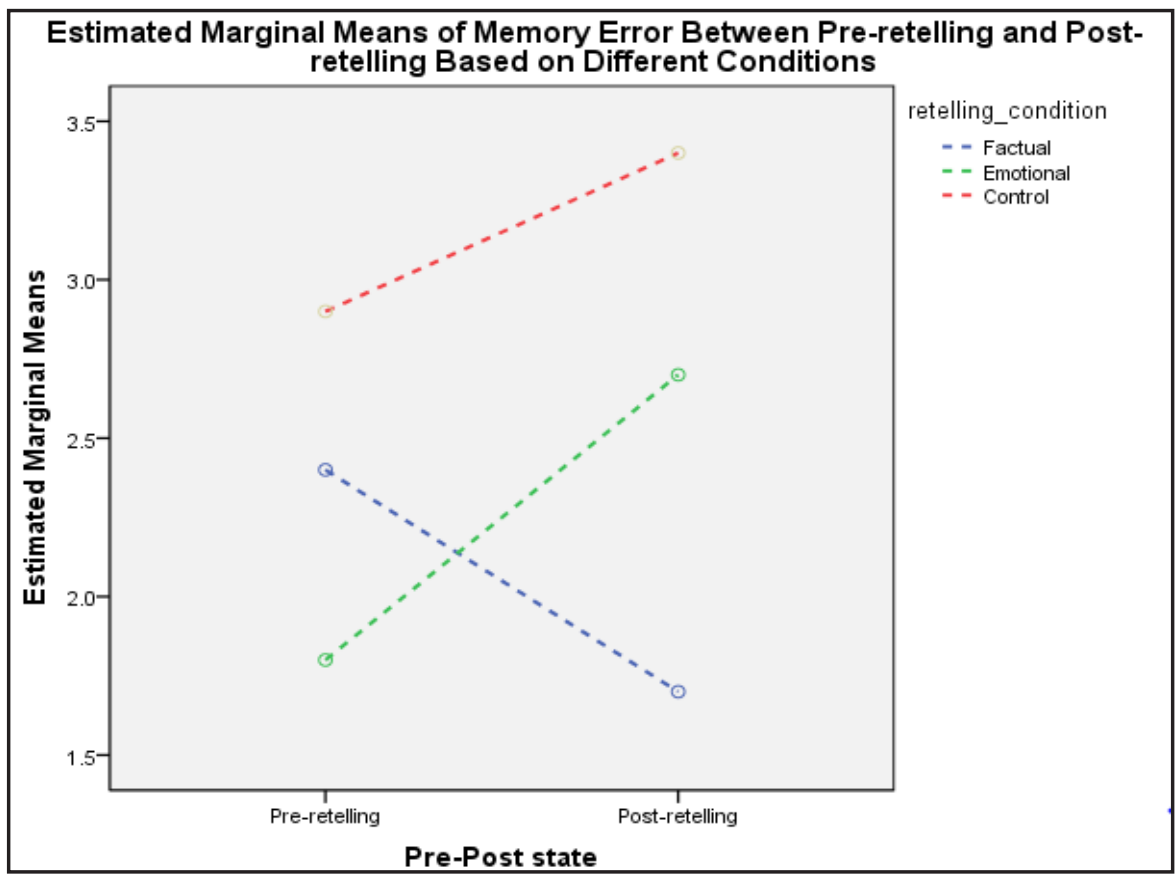

Figure 4: Interaction effect of retelling by test-retest on memory error

error performance.

In Table 2, the main effect of Retelling was found to be significant $(F=17.83, p<0.01)$. A significant decrease in memory errors was observed between pre and post retelling state in the factual retelling group compared to the other groups. A significant increase in memory errors in both the emotional and factual retelling conditions were also identified. A significant difference was also found between the Test-retest stage $(F=7.23$, $p<0.05)$. A significant interaction effect of Retelling by Test-retest in memory error was also evident $(F=16.71, p<0.01$, see Figure 4)

Figure 4 shows the interaction between retelling conditions and prepost retelling state. The average mean of memory error in factual retelling was observed to decrease between the pre-retelling and post-retelling state. However, the emotional and control condition showed a significant increases in memory errors score, the gradient of emotional condition is larger than control condition. Although memory errors in both the retelling conditions increased, the degree of differences between pre- and post-test in emotional retelling condition is more than that of control condition. 


\section{DISCUSSION AND CONCLUSION}

This study examined the effect of different foci of retelling on memory accuracy and error in eyewitness testimony. The findings are consistent with that of Soleti et al. (2012), showing a significant difference in memory accuracy and error in Emotional, Factual and Control Retelling condition, as well as at Test-retest stage. Emotional retelling condition decreased the proportion of correct details and increased the errors in free recall between the pre and post retelling conditions. The result shows that participants made more errors in postretelling test after being compared with the pre-retelling condition. In contrast, factual retelling was found to enhance the memory by increasing the proportion of correct details and decreasing the memory error in free recall. When comparing the results of pre-retelling test with post-retelling test in factual retelling condition, participants listed more correct details about the event.

The baleful effect of emotional retelling on memory might be due to the focus of attention of participants during the encoding process (Dudukovic et al., 2009). In the retelling session, the participants in emotional retelling condition were focusing on the personal thoughts and emotional reactions to event, but not the factual details of the video. Dudukovic et al. (2009) findings showed that if someone's attention is not focus on that particular information, the information will not be encoded properly and thus will be harder to recall that information. However, in the factual retelling condition, the main focus was on the details of the event. During the factual retelling phase, participants discussed their information with each other and this proses enhanced the memory encoding. Apart from that, participants would realize their mis-information during the factual retelling and correct it. This explained the reason why memory errors in factual retelling condition were reduced during the retest recall session. For the control condi- tion, the memory performance decreased although participants did unrelated task (playing a number game). As mentioned by Loftus and Ketcham (1991), information does not retain as it is in our memory even though it has been observed and remembered carefully. Memory becomes vague with the passage of time.

This current findings support the study of Anderson and Shimamura (2005) as well as Soleti et al. (2012). Soleti et al. (2012) who found that memory performance of an eyewitness declines when he or she emphasized on feelings and emotions during retelling phase, since focusing on emotion causes a decreased in perceptual and contextual qualities of memory trace. Individuals who focus on personal feelings and emotional reactions will cause a decreased in perceptual and contextual qualities of memory trace. Hence, memory error increased after the emotional retelling phase.

This study contributes to the methodology in testing memory accuracy and error. A higher fidelity to the real crime situation was imitated in this methodology - participants were requested to discuss in a group during the retelling phase, rather than attempting it individually. This method is similar to real life situation when someone is exposed to a criminal event. Solet et al. (2012) and Rime (2009) emphasise that eyewitnesses usually compare and discuss their experiences with other people especially when they witness a crime, therefore participants in this study were instructed to discuss their information with each other to replicate the same situation.

The present study still has some limitations. During retelling session, although participants were given instructions to follow the correct execution of task, some participants tried to switch the topic of discussion from factual to emotional or emotional to factual. This situation might affect the accuracy of participants' recollections. Future research could replicate 
this experiment by adding another experimental condition that allows participants to discuss other issues they like during the retelling session. This will increase fidelity to the real crime scene. Further research using qualitative method would also yield richer data on the information processing and accuracy and error in eyewitness memory.

\section{ACKNOWLEDGEMENTS}

The authors are very grateful for the cooperation extended by participants who are undergraduate students of Universiti Malaysia Sarawak.

\section{REFERENCES}

Anderson, L., \& Shimamura, A. P. (2005). Influences of emotion on context memory while viewing film clips. American Journal of Psychology, $118(3), 323-337$.

Bohannon, J. (2014). How reliable is eyewitness testimony? Retrieved from http://news.sciencemag.org/policy/2014/10/how-reliable-eyewitness-testimony-scientists-weigh.

Brown, R., \& Kulik, J. (1977). Flashbulb memories. Cognition, 5(1), 73-99.

Core, D. (2013). Rompakan bersenjata di kedai arak pada siang hari. Retrieved from https://www.youtube. $\mathrm{com} /$ watch? $\mathrm{v}=\mathrm{NZ} 13 \mathrm{Zg} 51 \mathrm{MVk}$

Davies, G. M., \& Logie, R. H. (1993). Memory in everyday life. The Netherlands: Elsevier Science Publishers.

Dudukovic, N. M., Dubrow, S., \& Wagner, A. D. (2009). Attention during memory retrieval enhances future remembering. HHS Journal, 37(7), 953-961.

Edelstein, R. S., Alexander, K. W., Goodman, G. S., \& Newton, J. W. (2004). Emotion and eyewitness memory. In D. Reisberg \& P. Hertel (Eds.), Memory and Emotion (pp.308-346). New York, NY: Oxford University Press.

Ellis, H. C., \& Hunt, R.R. (1993). Fundamentals of cognitive psychology. US: Wm. C. Brown Communications, Inc.

Eysenck, H. J. (2006). The organization of personality. Journal of Personality, 20(1), 101-117.

Loftus, E. F., Loftus, G. R., \& Messo, J. (1987). Some facts about weapon focus. Law and Human Behavior, 11(1), 55-62.

Loftus, E., \& Ketcham, K. (1991). Witness for the defense: The accused, the eyewitness, and the expert who puts memory on trial. New York: St. Martin's Press.

Marsh, E. J., Tversky, B., \& Hutson, M. (2005). How eyewitnesses talk about events: Implications for memory. Applied Cognitive Psychology, 19(5), 531-544.

Ochsner, K. N. (2000). Are affective events richly recollected or simply familiar? The experience and process of recognizing feelings past. Journal of Experimental Psychology: General, 129(2), 242-261.

Rime, B. (2009). Emotion elicits the social sharing of emotion: Theory and empirical review. Emotion Review, l(1), 60-85.

Soleti, E., Curci, A., Bianco, A., \& Lanciano, T. (2012). Does talking about emotions influence eyewitness memory? The role of emotional vs. factual retelling on memory accuracy. Europe's Journal of Psychology, 8(4), 632-640.

Wells, G. (2014). Eyewitness testimony is far from perfect. Retrieved from http://m.livescience.com/48966eyewitness-testimony-is-far-fromperfect.html

Whitaker, S. (2013). What role does emotion play in memory? Retrieved from http:/astudentofpsychology. blogspot.com/2013/06/what-role- 
does-emotion-play-in-memory.

$\mathrm{html}$

Zimmermann, K. A. (2014). Memory

definition \& types of memory.

Retrieved from http://www.li-

vescience.com/43713-memory.

html 